\title{
A Method of Calculating the Interaction Energy between Particles in Minerals Flotation
}

\author{
J. Yao, ${ }^{1}$ H. Han, ${ }^{1}$ Y. Hou, ${ }^{2}$ E. Gong, ${ }^{1}$ and W. Yin ${ }^{1}$ \\ ${ }^{1}$ College of Resources and Civil Engineering, Northeastern University, Shenyang 110819, China \\ ${ }^{2}$ School of Mining Engineering, University of Science and Technology Liaoning, Anshan 114051, China \\ Correspondence should be addressed to Y. Hou; 1105519675@qq.com and W. Yin; yinwanzhong@mail.neu.edu.cn
}

Received 29 November 2015; Accepted 6 March 2016

Academic Editor: Yannis Dimakopoulos

Copyright (c) $2016 \mathrm{~J}$. Yao et al. This is an open access article distributed under the Creative Commons Attribution License, which permits unrestricted use, distribution, and reproduction in any medium, provided the original work is properly cited.

Extended-DLVO (Derjaguin-Landau-Verwey-Overbeek) theory is applied to calculating the interaction energy between particles in flotation process in the paper. This study investigates and compares the floatability of magnesite, dolomite, serpentine, and quartz in single mineral flotation and artificial mixture flotation with DDA as collector. The results showed that when the $\mathrm{pH}$, dissolved ions, and competitive adsorption had a minor influence on their floatability, fine magnesite and dolomite largely decreased the recovery of quartz. SEM analysis on the flotation products demonstrated severe masking of fine particles on the surface of quartz. The Extended-DLVO theory was applied to calculate the interaction energy between the minerals, and the results showed that the interaction forces between magnesite and quartz, serpentine and quartz, and dolomite and quartz were attractive; therefore, fine magnesite, serpentine, and dolomite particles are easily masked on the surface of quartz. The calculation results agree with the experiment results and explain the mechanism of particles interaction and the reasons for the inconsistency in single mineral flotation and actual ore flotation. The particles interaction behavior is important in flotation process, and the interaction energy calculation is helpful for evaluating this behavior.

\section{Introduction}

Single mineral flotation tests are widely used as a reference in flotation separation research to investigate the floatability of minerals for evaluating actual ore flotation methods [1, 2]. However, in most cases, the recovery of some minerals exhibits large differences in the single mineral flotation tests and actual ore flotation methods under the same flotation conditions, which reveals that the interactions of minerals affect the flotation behavior of the minerals. This interaction effect may be due to a combination of factors, including $\mathrm{pH}$ variation, dissolved ions [3], aggregation/dispersion [4, 5], competitive adsorption [6], or particle sizes [7, 8]. Among these reasons, the influence of fine particles plays an important role in many flotation processes [9-11].

The influence of fine particles on the flotation separation of minerals is becoming increasingly important as new fine grained deposits are exploited [12, 13]. Fine particles float poorly and less selectively under normal flotation conditions and have detrimental effects on the recovery of other minerals. Previous research has showed an interesting phenomenon in that fine mineral particles have interactive effects with coarse particles of other minerals through which coarse particles are concealed by masking of the fine particles. Such an interactive effect between minerals has widely been reported in slime coating $[14,15]$, carrier flotation, or flocculation flotation $[13,16,17]$ research.

Lange et al. [18] investigated the behavior of fine and coarse sphalerite in microflotation and aggregation studies. They used online particle size distribution techniques for obtaining direct evidence of particle interactions within a conditioning pulp and observed evidence of particle interactions using optical microscopy. They found that fine particles exhibit poor flotation response, and, in the presence of coarse particles at low $\mathrm{pH}$, a high percentage of fine particles were recovered, indicating the occurrence of finecoarse particle aggregation ("piggy-backing") mechanism. The surface properties of minerals also play an important role in determining their separation from each other in flotation processes. The interactive effects between minerals 
could be partially explained by evaluating the surface tension and interacting energy. Lu and Song [19] investigated the flocculation behavior of fine mineral particles, which is hydrophobic owing to the surfactant, and the mechanism of hydrophobic flocculation. Their results showed that changes in wettability of mineral surface significantly affect the stability of fine particle suspensions. The DLVO (DerjaguinLandau-Verwey-Overbeek) theory is a quantitative theory of the stability (aggregation or dispersion) of charged colloidal particles. However, the hydrophobization of particle surfaces is often accompanied by a distinct flocculation, which cannot be interpreted by the DLVO theory. The potential energy of hydrophobic interactions between mineral particles owing to the surfactant is much higher than that resulting from double layer or van der Waals interactions. The Extended-DLVO theory considering hydrophobic and hydrophilic interactions may be able to explain the fine-coarse particle interactions in flotation processes.

In the abovementioned research, the positive interactive effect between mineral particles was utilized for carrier flotation or flocculation flotation. However, the negative effects also affected the flotation process and strongly decreased the efficiency of mineral processing. In this study, the negative interactive effect, especially fine-coarse particle interaction, between different minerals, and its mechanism are investigated. Microflotation tests of single mineral and artificial mixtures of magnesite, dolomite, and quartz with DDA as the collector are conducted, and the results are compared and verified by the theoretical predictions of the ExtendedDLVO theory based on van Oss's interaction energy calculation. The electrokinetic potential, zero point of charge, and contact angles of pure magnesite, dolomite, and quartz, with and without DDA, were determined to obtain the surface tension parameters. Further, the experimental and theoretical calculation results of the particles interaction are provided for magnesite-dolomite-quartz cationic flotation separation as an example. This theoretical calculation method can quantitatively define the existence and extent of particles interaction in flotation processes.

\section{Theoretical}

The classical DLVO theory is a quantitative theory of the stability (aggregation or dispersions) of charged colloidal particles, which was developed and published independently by Derjaguin and Landau in Russia in 1941 and by Verwey and Overbeek in Netherlands in 1948 [20]. It is expressed as follows:

$$
V_{\mathrm{TD}}=V_{W}+V_{E}
$$

The classical DLVO theory only considers the electrostatic and van der Waals interaction and fails when the surfaces are very hydrophilic or hydrophobic, for which the contact angle of water is less than $15^{\circ}$ (hydration forces) or greater than $64^{\circ}$ (hydrophobic forces) [21]. However, the hydrophobic aggregation of particles can be explained in the Extended-DLVO theory with respect to polar interfacial interaction [22-24]. In the Extended-DLVO theory, the total interaction energy comprises the following components:

(1) van der Waals interaction, $V_{W}$.

(2) Electrical (Coulombic) interactions under constant potential, $V_{E}$.

(3) Hydrophobic or hydration interaction, $V_{H}$ :

$$
V_{\mathrm{TED}}=V_{W}+V_{E}+V_{H} .
$$

The magnitude of the above interaction energies is calculated according to the following expressions:

(1) van der Waals interaction, $V_{A}[25,26]$ :

$$
V_{W}=-\frac{A_{132}}{6 H} \frac{R_{1} R_{2} f\left(P_{0}\right)}{R_{1}+R_{2}},
$$

where

$$
A_{132} \approx\left(\sqrt{A_{11}}-\sqrt{A_{33}}\right)\left(\sqrt{A_{22}}-\sqrt{A_{33}}\right) \text {, }
$$

for $P_{0}=2 \pi H / \lambda<0.5$,

$$
f\left(P_{0}\right)=\frac{1}{1+1.77 P_{0}},
$$

for $0.5<P_{0}<\infty$,

$$
f\left(P_{0}\right)=-\frac{2.45}{60 P_{0}}+\frac{2.17}{180 P_{0}^{2}}-\frac{0.59}{420 P_{0}^{3}} .
$$

(2) Electrical (Coulombic) interactions under constant potential, $V_{E}[27,28]$ :

$$
V_{E}=\frac{\pi \varepsilon_{0} \varepsilon_{r} R_{1} R_{2}}{R_{1}+R_{2}}\left(\varphi_{1}^{2}+\varphi_{2}^{2}\right)\left[\frac{2 \varphi_{1} \varphi_{2}}{\varphi_{1}^{2}+\varphi_{2}^{2}} p+q\right],
$$

where

$$
\begin{aligned}
& p=\ln \left[\frac{1+\exp (-\kappa H)}{1-\exp (-\kappa H)}\right], \\
& q=\ln [1-\exp (-2 \kappa H)], \\
& \kappa=\left(\frac{2 e^{2} n_{0} z^{2}}{\varepsilon_{0} \varepsilon_{r} k T}\right)^{1 / 2}=\left(\frac{2 e^{2} N_{A} c z^{2}}{\varepsilon_{0} \varepsilon_{r} k T}\right)^{1 / 2} .
\end{aligned}
$$

(3) Polar interfacial interaction $[29,30]$ :

$$
V_{H}=2 \pi \frac{R_{1} R_{2}}{R_{1}+R_{2}} h_{0} V_{H}^{0} \exp \left(\frac{H_{0}-H}{h_{0}}\right) .
$$

For calculating $V_{H}$ at distance $H$, the "decay length" $h_{0}$ is necessary, but its value is still under debate and ranges from $0.2 \mathrm{~nm}$ (for nonhydrogen bonded water molecules) [31] to $13 \mathrm{~nm}$ [32]. However, a reasonable value of $h_{0}$ seems to be about $1 \mathrm{~nm}$ [33]. $H_{0}$ is the minimum equilibrium contact distance between particles; $H_{0}=0.163 \mathrm{~nm}$ according to van 
Oss [34]. The acid-base free energy per unit area between the surfaces can be calculated by the following equation:

$$
\begin{aligned}
V_{H}^{0} & =2\left[\sqrt{\gamma_{3}^{+}}\left(\sqrt{\gamma_{1}^{-}}+\sqrt{\gamma_{2}^{-}}-\sqrt{\gamma_{3}^{-}}\right)\right. \\
& \left.+\sqrt{\gamma_{3}^{-}}\left(\sqrt{\gamma_{1}^{+}}+\sqrt{\gamma_{2}^{+}}-\sqrt{\gamma_{3}^{+}}\right)-\sqrt{\gamma_{1}^{+} \gamma_{2}^{-}}-\sqrt{\gamma_{1}^{-} \gamma_{2}^{+}}\right] .
\end{aligned}
$$

According to van Oss et al. [34-38], the contact angle is related to the polar (Lewis acid-base, $\mathrm{AB}$ ) and apolar (Lifshitz-van der Waals, LW) components of the surface energy of solids, as well as the solid-liquid interfacial energy. They derived the following equation:

$$
(1+\cos \theta) \gamma_{L}=2\left(\sqrt{\gamma_{S}^{\mathrm{LW}} \gamma_{L}^{\mathrm{LW}}}+\sqrt{\gamma_{S}^{+} \gamma_{L}^{-}}+\sqrt{\gamma_{S}^{-} \gamma_{L}^{-}}\right)
$$

Because most oxidized minerals have monopolar surface, for which, $\gamma_{S}^{+} \approx 0$, (1) can be simplified as

$$
(1+\cos \theta) \gamma_{L}=2\left(\sqrt{\gamma_{S}^{\mathrm{LW}} \gamma_{L}^{\mathrm{LW}}}+\sqrt{\gamma_{S}^{-} \gamma_{L}^{-}}\right)
$$

Thus, by contact angle $(\theta)$ measurements with only two different liquids (both must be polar) with known $\gamma_{L}^{\mathrm{LW}}, \gamma_{L}^{+}$, and $\gamma_{L}^{-}$values and by using (12) twice, the values $\gamma_{S}^{\mathrm{LW}}$ and $\gamma_{S}^{-}$of magnesite, dolomite, serpentine, and quartz can be determined.

The Hamaker constant can be determined by $\gamma_{S}^{\mathrm{LW}}$ using the following equation [39]:

$$
A=1.51 \times 10^{-21} \gamma_{S}^{\mathrm{LW}} .
$$

The nomenclature used in the above equations is listed below:

\section{A: Hamaker constant (J).}

$A_{132}$ : effective Hamaker constant of materials 1 and 2 in medium $3(\mathrm{~J})$.

$c$ : concentration $\left(\mathrm{mol} \cdot \mathrm{m}^{-3}\right)$.

$e$ : electronic charge, $1.602 \times 10^{-19} \mathrm{C}$.

$H$ : minimum separation distance between two spheres (m).

$N_{A}$ : avogadro number, $6.023 \times 10^{23} \mathrm{~mol}^{-1}$.

$k$ : Boltzmann's constant, $1.3806 \times 10^{-23} \mathrm{~J} \cdot \mathrm{K}^{-1}$.

$P_{0}$ : parameter in (6), upon calculating the retardation coefficient.

$R_{1}, R_{2}$ : radius of particles 1 and $2(\mathrm{~m})$.

$T$ : temperature $(\mathrm{K})$.

$V_{W}$ : interaction energy due to van der Waals forces (J).

$V_{E}$ : interaction energy due to electrical double layer effects $(\mathrm{J})$.

$V_{H}$ : interaction energy due to hydration/hydrophobic effects $(J)$.

$V_{H}^{0}$ : the acid-base free energy per unit area $(\mathrm{J})$.

$V_{\text {TD }}$ : total interaction energy by DLVO theory (J).
$V_{\mathrm{TED}}$ : total interaction energy by E-DLVO theory (J). $z$ : valence.

$\gamma_{i}^{\mathrm{LW}}$ : parameter of apolar (Lifshitz-van der Waals) component of surface tension of compound $i$.

$\lambda$ : wavelength of intrinsic oscillations of atoms $(\mathrm{m} ; \lambda$ $\left.=10^{-7} \mathrm{~m}\right)$.

$\gamma_{i}^{-}$: parameter of polar component of the surface tension of compound $i$, donating electron or accepting proton.

$\gamma_{i}^{+}$: parameter of polar component of the surface tension of compound $i$, donating proton or accepting electron.

$\epsilon_{o}$ : permittivity of free space, $8.854 \times 10^{-12} \mathrm{~F} \cdot \mathrm{m}^{-1}$.

$\epsilon_{r}$ : relative permittivity (for water $\epsilon_{r}=81$ ).

$\kappa$ : Debye-Hückel parameter $\left(\mathrm{m}^{-1}\right)$.

$\psi_{1}, \psi_{2}$ : zeta-potential of particles 1 and $2(\mathrm{~V})$.

\section{Experimental}

3.1. Samples and Reagents. Pure magnesite $\left(\mathrm{MgCO}_{3}\right)$, dolomite $\left(\mathrm{CaMg}\left(\mathrm{CO}_{3}\right)_{2}\right)$, serpentine $\left.\left(\mathrm{Mg}_{6}\left[\mathrm{Si}_{4} \mathrm{O}_{10}\right](\mathrm{OH})_{8}\right]\right)$, and quartz $\left(\mathrm{SiO}_{2}\right)$ ore samples were obtained from Haicheng, Liaoning Province, China. The high-grade lump magnesite, dolomite, serpentine, and quartz crystals were carefully selected to avoid cracks and inclusions for the contact angle measurements. The ore samples were crushed, handpicked, and then dry-ground with a porcelain ball mill and drysieved to obtain the size fractions $(-100+65) \mu \mathrm{m}$ for the single mineral flotation tests. The $-5 \mu \mathrm{m}$ fractions of magnesite, dolomite, and serpentine were obtained by the elutriation method and used for artificial mineral flotation tests and zeta-potential measurements. The minerals were stored in a desiccator with nitrogen atmosphere. The results of chemical analysis of the samples are listed in Table 1, and the X-ray diffraction (XRD) patterns of the samples are shown in Figures 1-4, which indicate that the purities of magnesite, dolomite, and quartz were $98.66 \%$, 98.98\%, and $99.78 \%$, respectively. Distilled water and analytical grade chemicals such as $\mathrm{HCl}, \mathrm{NaOH}$, and dodecylamine (DDA) were used in all experiments.

3.2. Flotation Tests. Single mineral flotation tests were carried out in a mechanical agitation flotation machine. The impeller speed was fixed at $1800 \mathrm{r} / \mathrm{min}$. The single mineral flotation test was prepared by adding $3.0 \mathrm{~g}$ of minerals to $30 \mathrm{~mL}$ of solutions. After adding the desired amount of reagents, froth flotation was carried out during which a concentrate was collected. The floated and unfloated particles were collected, filtered, and dried. The flotation recovery was calculated based on solid weight distributions between the two products. The $30 \mathrm{~mL}$ mechanical agitation flotation machine was also used in the artificial mineral mixture flotation; the size fraction of quartz was $-100+65 \mu \mathrm{m}$ and that of magnesite, dolomite, and serpentine was $-5 \mu \mathrm{m}$. For two minerals' mixture, the total weight of mixed minerals was $3.0 \mathrm{~g}$, and, 
TABLE 1: Results of chemical analysis of the single minerals.

\begin{tabular}{|c|c|c|c|c|c|c|}
\hline Samples & $\mathrm{MgO} / \%$ & $\mathrm{CaO} / \%$ & $\mathrm{SiO}_{2} / \%$ & $\mathrm{Al}_{2} \mathrm{O}_{3} / \%$ & $\mathrm{FeO} / \%$ & Purity $/ \%$ \\
\hline Magnesite & 47.17 & 0.40 & 0.17 & - & - & 98.66 \\
\hline Dolomite & 22.85 & 29.21 & 0.74 & 0.19 & 0.01 & 98.98 \\
\hline Serpentine & 41.6 & 1.67 & 40.95 & 1.56 & - & 95.41 \\
\hline Quartz & - & - & 99.78 & - & 0.05 & 99.78 \\
\hline
\end{tabular}

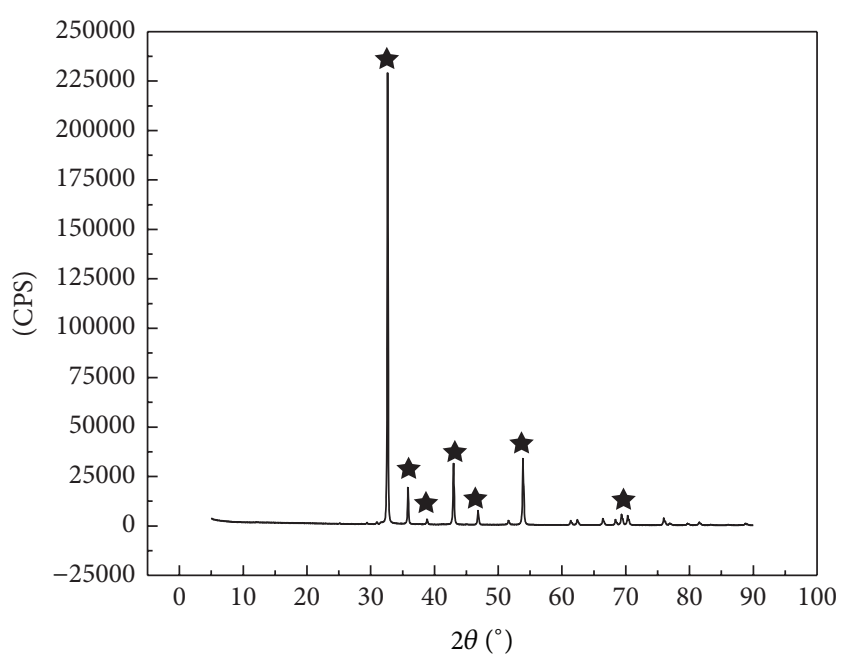

Magnesite

FIGURE 1: XRD pattern of magnesite sample.

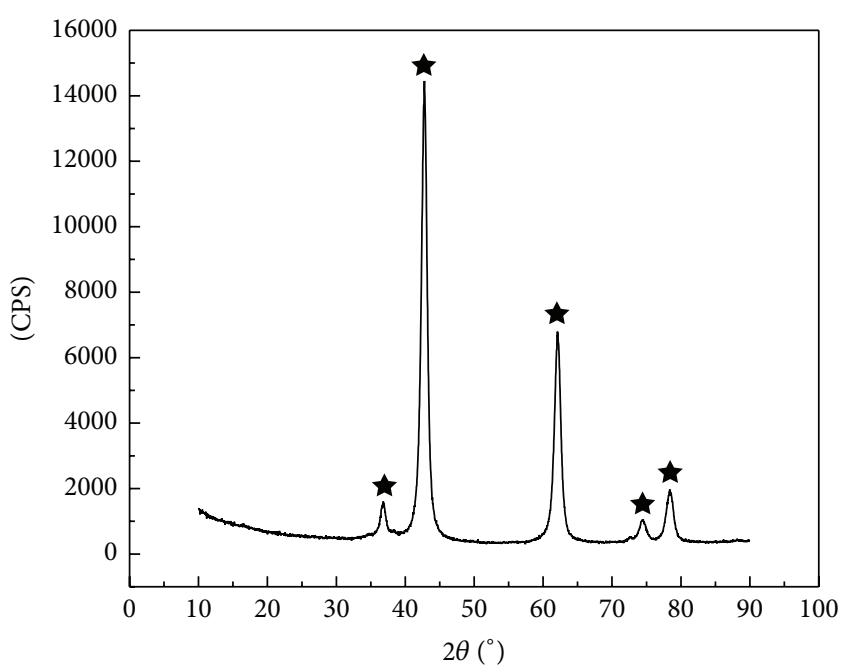

Serpentine

FIGURE 2: XRD pattern of serpentine sample.

for the three minerals' mixture, $2.7 \mathrm{~g}$ of magnesite, $0.3 \mathrm{~g}$ of quartz, and proportional amount of dolomite were mixed. The products were filtrated, dried, and weighed for assessing the recovery by multielemental chemical analysis. The $\mathrm{pH}$ of the mineral suspension was adjusted to a desired value by adding $\mathrm{NaOH}$ or $\mathrm{HCl}$ stock solutions. There was a $2 \mathrm{~min}$ conditioning period after the reagent addition. The flotation

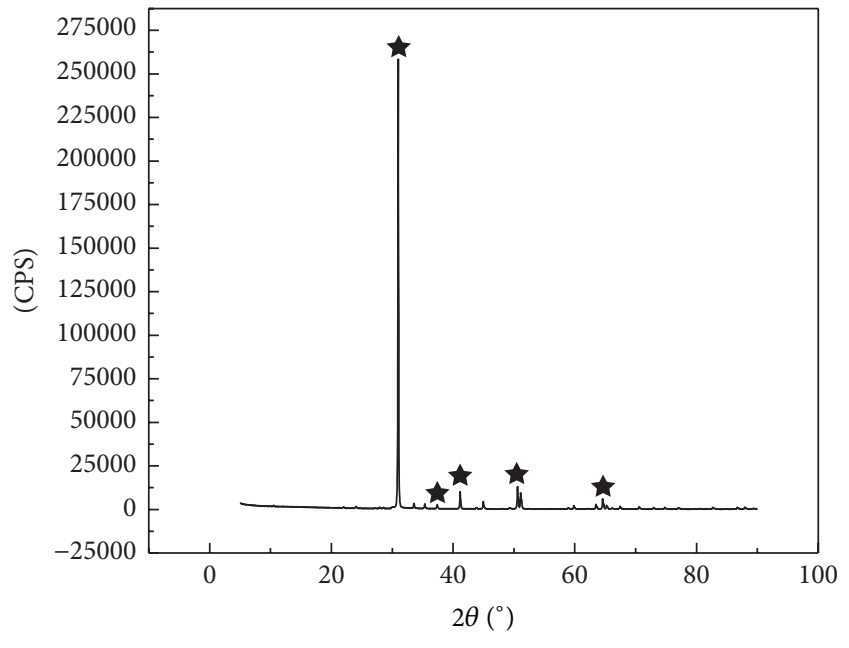

Dolomite

FIGURE 3: XRD pattern of dolomite sample.

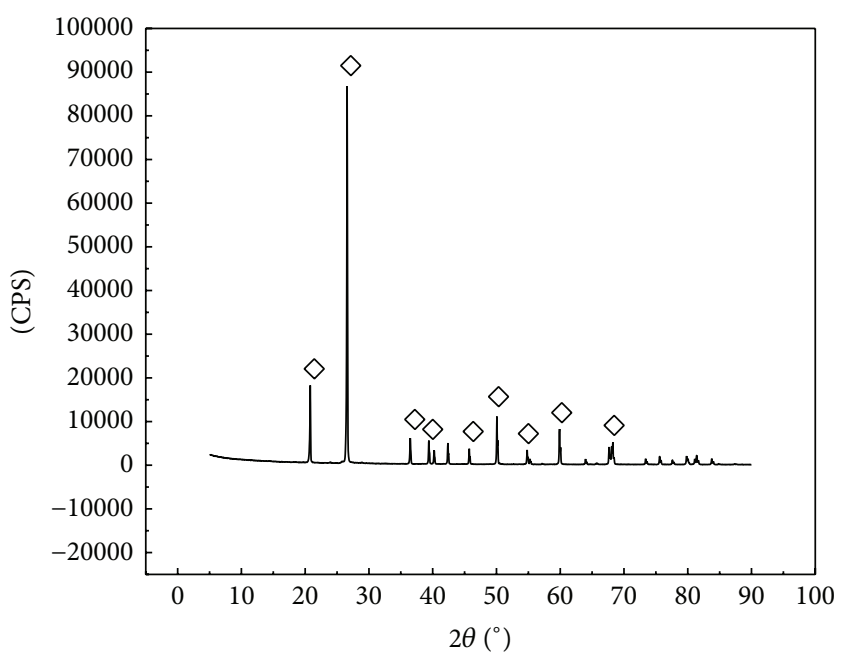

$\diamond$ Quartz

FIGURE 4: XRD pattern of quartz sample.

was conducted for a total of $3 \mathrm{~min}$. The errors in the recovery were found to be within $3.0 \%$ after at least three tests under each condition, and the average values were reported.

3.3. Zeta-Potential Measurements. To measure the zetapotential of magnesite, dolomite, and quartz, experiments were carried out using the microelectrophoresis method. 
Electrophoretic mobility of the particles was measured with a Nano-ZS90 Micro-Electrophoresis Apparatus. $1.5 \mathrm{~g}$ each of magnesite, dolomite, serpentine, and quartz was conditioned in $100 \mathrm{~mL}$ of distilled water and in DDA acetic solution $(8.6 \times$ $10^{-4} \mathrm{M}$ ) for $10 \mathrm{~min}$, and the suspension was allowed to stand for another $15 \mathrm{~min}$ to allow settling of the larger particles. Fine particles in the removed suspension were used in the measurements. The measurements were repeated 20 times for each data point, and the average of these measurements was used for the electrokinetic potentials. The $\mathrm{pH}$ of the suspensions was adjusted using $\mathrm{HCl}$ and $\mathrm{NaOH}$. To assess the accuracy of the measurements, the zeta-potential of at least five independent suspensions was evaluated. The average values were considered, and the measurement errors were found to be within $5 \mathrm{mV}$.

3.4. Contact Angle Measurements. High-purity magnesite, dolomite, and quartz samples were used in this study. The high-grade lump ores were cut into slices of length about $20 \mathrm{~mm}$, width $10 \mathrm{~mm}$, and thickness $3 \mathrm{~mm}$, and they were first embedded using epoxy resin. The embedded specimens were polished using 60-, 240-, 500-, and 1000-grit silicon carbide papers sequentially. The initial polishing was done using $0.05 \mu \mathrm{m}$ aluminum oxide powder. Upon passing from one polishing material to the next finer grade, the polished surface of the sample was washed with distilled water to remove any traces of the polishing powder. The sessile drop technique was used for contact angle measurements with a JC2000A contact angle goniometer, with an accuracy of $\pm 1^{\circ}$. The sample disc treated with DDA acetic solution $\left(8.6 \times 10^{-4} \mathrm{M}\right)$ and dried in vacuum was placed in a rectangular glass chamber, and a liquid drop was introduced onto the substrate through a microsyringe. The needle was maintained in contact with the drop. Special care was taken in these measurements to avoid vibrations of the needle and to avoid distortion of the drop shape by the needle. The receding contact angles were measured for different liquid drops with 3-4 mm drop base diameter. The measurements were repeated six times under each condition, and the average value was reported. All measurements were carried out at $25 \pm 2^{\circ} \mathrm{C}$.

\section{Results and Discussion}

4.1. Microflotation Test. The objective of the microflotation test was to investigate the interaction of fine magnesite, dolomite, serpentine, and quartz particles in the flotation process. The single mineral floatability of magnesite, dolomite, serpentine, and quartz with surfactant DDA acetic solution and the influence of $\mathrm{pH}$ on their flotation were investigated first.

The single mineral flotation recovery of magnesite, dolomite, serpentine, and quartz with different DDA acetic dosages is shown in Figure 5. The recovery of quartz could reach $96.66 \%$, the recovery of dolomite could reach $49 \%$, and that of serpentine was only $22 \%$ with DDA concentration of $8.6 \times 10^{-4} \mathrm{M}$, but magnesite hardly floats under this condition. Figure 6 shows the flotation recovery of magnesite, dolomite, serpentine, and quartz as a function of $\mathrm{pH}$ with

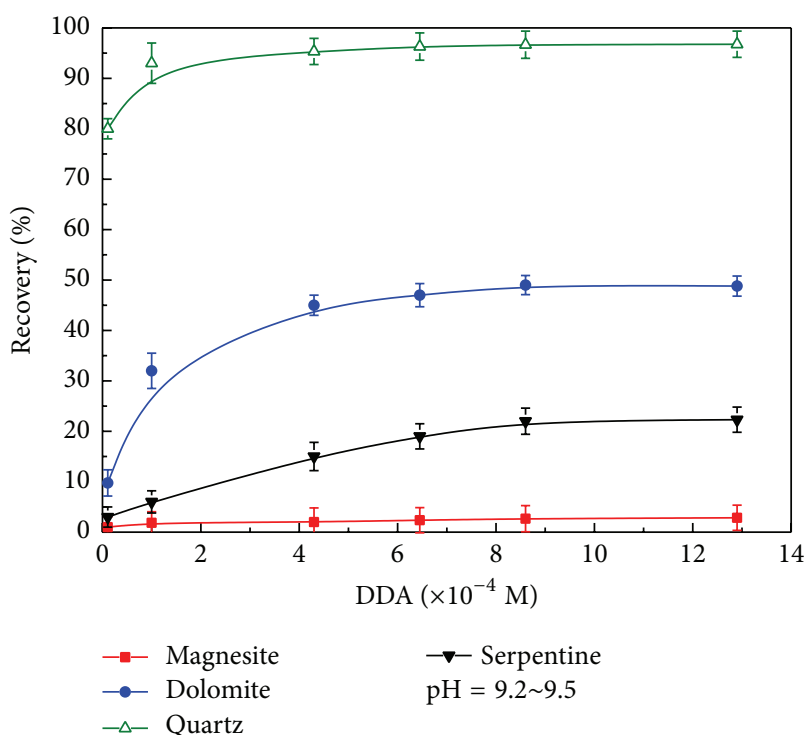

FIGURE 5: Influence of DDA dosage on the recovery of magnesite, dolomite, serpentine, and quartz.

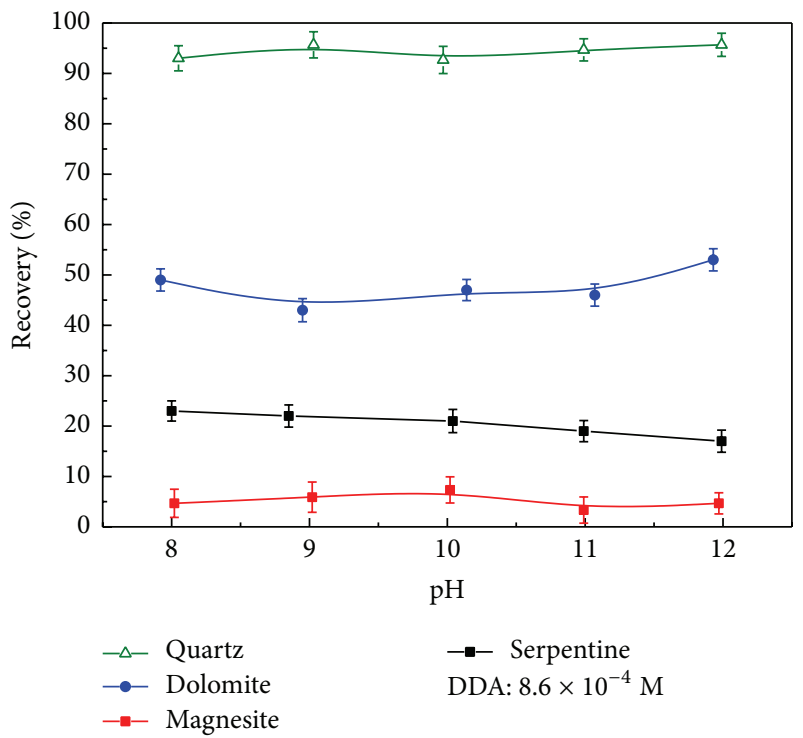

FIGURE 6: Influence of $\mathrm{pH}$ on the recovery of magnesite, dolomite, serpentine, and quartz.

DDA concentration of $8.6 \times 10^{-4} \mathrm{M}$. The floatability of these minerals had small variations within a wide $\mathrm{pH}$ range.

To avoid competitive adsorption, an adequate dosage of DDA $\left(8.6 \times 10^{-4} \mathrm{M}\right)$ was used for the artificial mixture flotation. Figure 7 shows the flotation recovery of magnesite and quartz in the artificial mixture. When the quartz content was $5 \%$, the recovery of quartz was reduced dramatically (from $96.66 \%$ to $37.15 \%$ ), and as the content increased, the recovery gradually increased. In contrast, the recovery of magnesite increased with increase in the quartz content. In the presence of fine magnesite particles, a high percentage of coarse quartz particles could not be recovered, indicating an apparent suppressing effect of fine magnesite on quartz. 


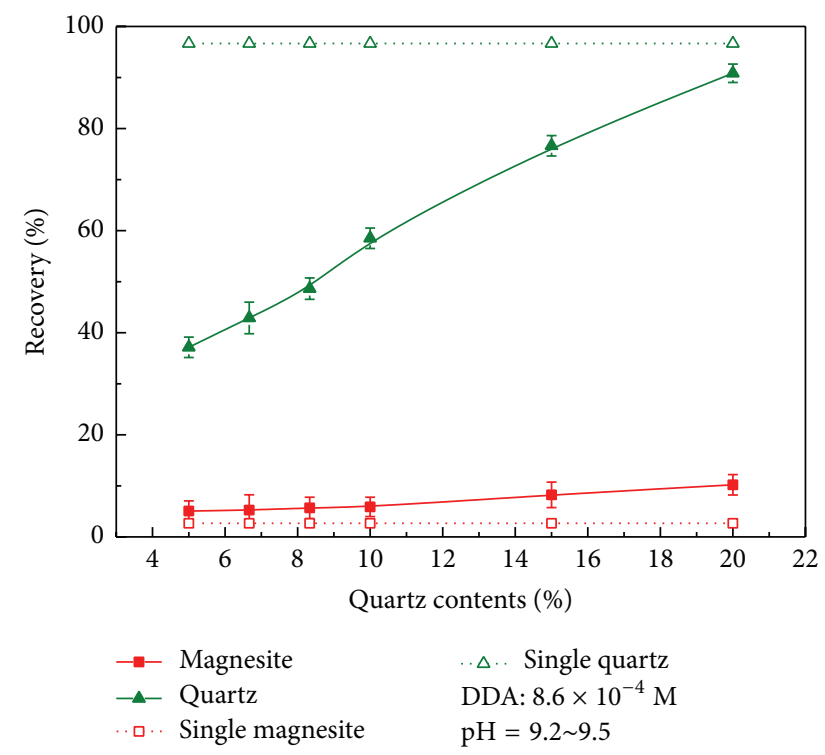

FIGURE 7: Influence of quartz content on the recovery of magnesite $(-5 \mu \mathrm{m})$ and quartz $(-100+65 \mu \mathrm{m})$ in the flotation of their artificial mixture.

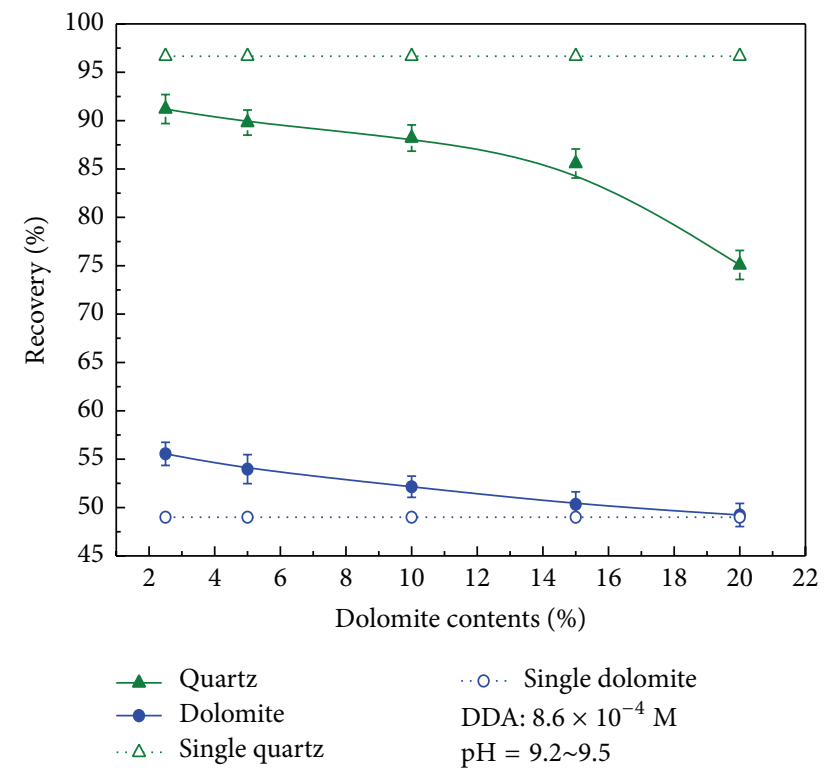

FIGURE 8: Influence of dolomite content on the recovery of dolomite $(-5 \mu \mathrm{m})$ and quartz $(-100+65 \mu \mathrm{m})$ in the flotation of their artificial mixture.

In the flotation of an artificial mixture of fine dolomite and coarse quartz, similar results are presented in Figure 8. The recovery of quartz reduced with an increase in the dolomite content. In contrast, the recovery of dolomite increased with an increase in the quartz content. Figure 9 shows the influence of fine serpentine on the flotation of quartz, which indicated that the fine serpentine particles also had suppressing effect on quartz. Figure 10 shows the flotation recovery of fine magnesite, fine dolomite, and coarse quartz. The recovery of quartz reduced with an increase in the

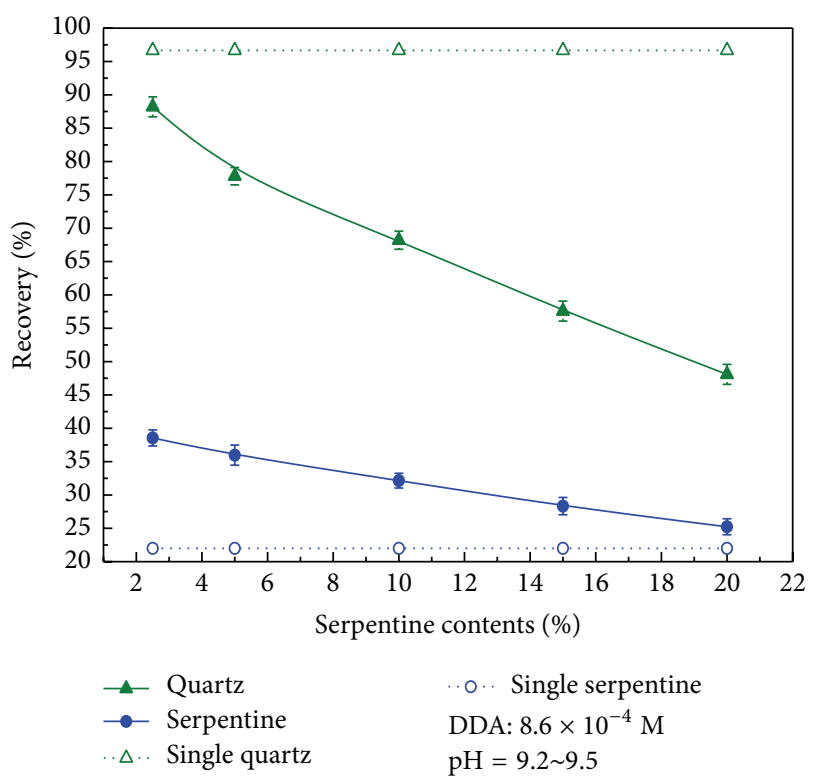

FIGURE 9: Influence of serpentine content on the recovery of serpentine $(-5 \mu \mathrm{m})$ and quartz $(-100+65 \mu \mathrm{m})$ in the flotation of their artificial mixture.

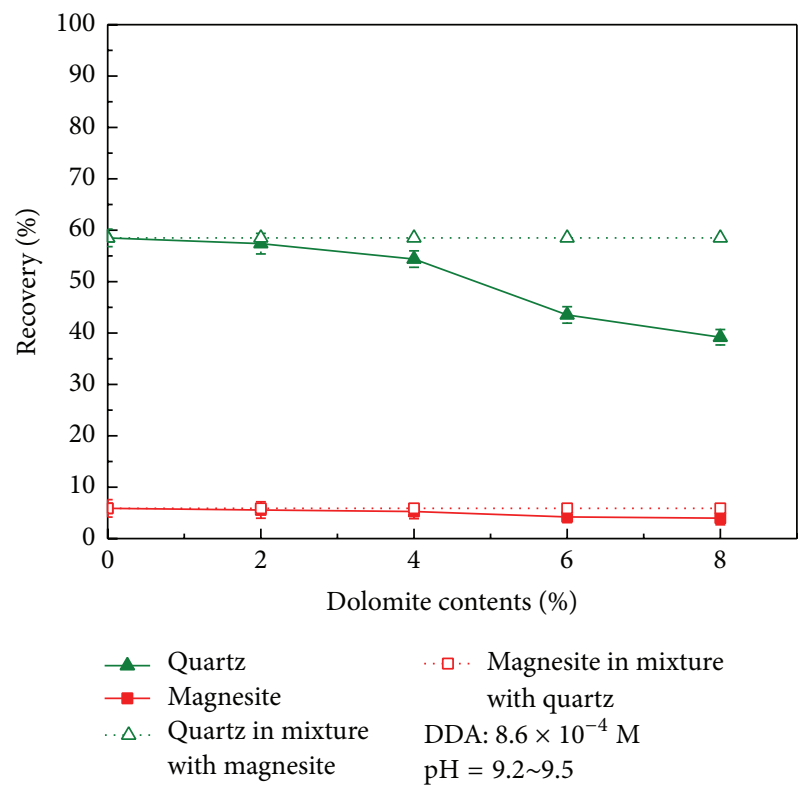

FIgURE 10: Influence of dolomite content on the recovery of dolomite $(-5 \mu \mathrm{m})$, magnesite $(-5 \mu \mathrm{m})$, and quartz $(-100+65 \mu \mathrm{m})$ in their artificial mixture.

dolomite content, but the recovery of magnesite was almost unchanged. The results indicate that particle interaction occurred between dolomite and quartz, but not between dolomite and magnesite.

The results above demonstrate that the recovery of minerals can be influenced in the presence of other fine mineral particles under certain conditions. However, the mechanism could be very complex because it is usually a combination of many factors, such as $\mathrm{pH}$ vibration, dissolved ions from 


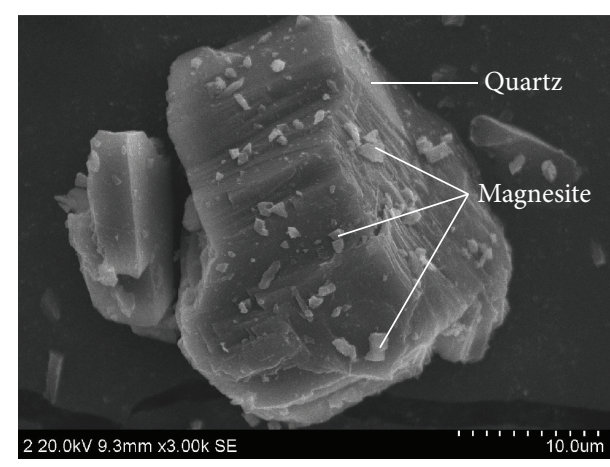

(a)

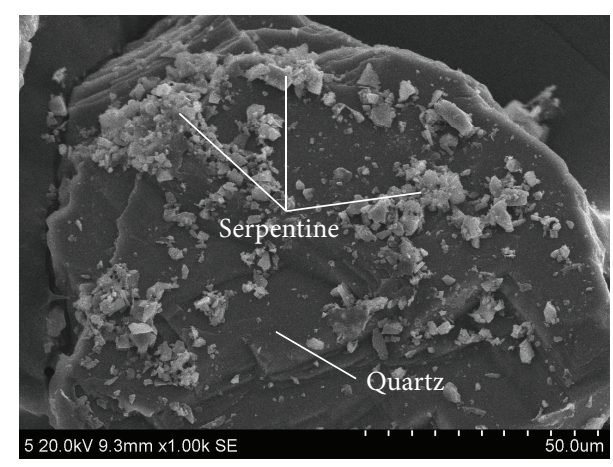

(b)

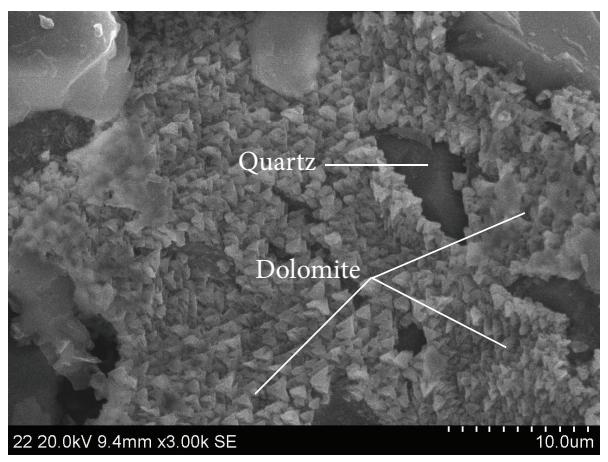

(c)

FIGURE 11: SEM analysis of the float product of (a) quartz-magnesite mixture, (b) serpentine-quartz mixture, and (c) quartz-dolomite mixture, exhibiting severe masking of fine magnesite and dolomite particles on quartz.

mineral surface, competitive adsorption of collector, and the entrainment effect [40-43]. However, in this case, the floatability of these minerals was insensitive to $\mathrm{pH}$ vibration, besides the floatability of quartz is insensitive to $\mathrm{Mg}^{2+}$ and $\mathrm{Ca}^{2+}$ with DDA as the collector, and the collector dosage was adequate. Therefore, the $\mathrm{pH}$, dissolved ions, and competitive adsorption are not factors affecting finecoarse particle interaction. Moreover, the recovery of quartz decreased considerably, and, hence, the entrainment effect is also ruled out as a factor. The results indicate that fine and coarse particles with different surface properties may interact and thus influence their individual flotation behavior. To validate this assumption, SEM analysis was conducted on the flotation product, and the interaction force between magnesite, dolomite, serpentine, and quartz particles was calculated based on the Extended-DLVO theory in order to quantitatively evaluate their aggregation/dispersion possibility. Zeta-potential and contact angles are measured to obtain the calculation parameters.

4.2. SEM Analysis. SEM analyses on the flotation product were conducted to examine the aggregation and masking phenomena. The SEM images in Figure 11 reveal severe masking. The fine magnesite and serpentine particles can adsorb on the coarse quartz surface, as shown in Figures 11(a) and 11(b), and, for the fine dolomite particles, this masking phenomenon is also clearly observed, as shown in Figure 11(c). This indicates that the adsorption of the collector on the quartz surface becomes harder, and, hence, the particles float less easily by the air bubble, which explains why magnesite, dolomite, and serpentine decreased the recovery of quartz. To understand the mechanisms and condition for the adsorption of fine magnesite, dolomite, and serpentine on the quartz surface, a criterion based on the interaction energy calculation of the Extended-DLVO theory will be introduced.

4.3. Zeta-Potential Analysis. Surface potential is one of the parameters needed to calculate the interaction energy, and it is also useful for evaluating the electrostatic adsorption. If the surfaces of two particles are oppositely charged, aggregation will occur and vice versa. The zeta-potentials of magnesite, dolomite, serpentine, and quartz in the absence and presence of DDA are given in Figures 12 and 13. Magnesite, dolomite, serpentine, and quartz have zero point of charge (z. p. c.) at $\mathrm{pH} 6.7,6.0,8.8$, and 2.0 , respectively. The results indicate that the surface potential shifted towards the positive side after reacting with DDA because, above the mineral's $\mathrm{z}$. p. c., the surfaces exhibit negative charge and positively charged DDA ions are adsorbed on surfaces. Owing to the reduction of $\mathrm{OH}^{-}$(potential determining) ions, the z. p. c. of magnesite, dolomite, serpentine, and quartz shifted to more alkaline $\mathrm{pH}$ values. Above the z. p. c., magnesite, dolomite, serpentine, and quartz have negative charge and DDA ions can be adsorbed on the mineral surfaces physically through electrostatic forces, thus resulting in the increase of positive surface charge of the mineral. 


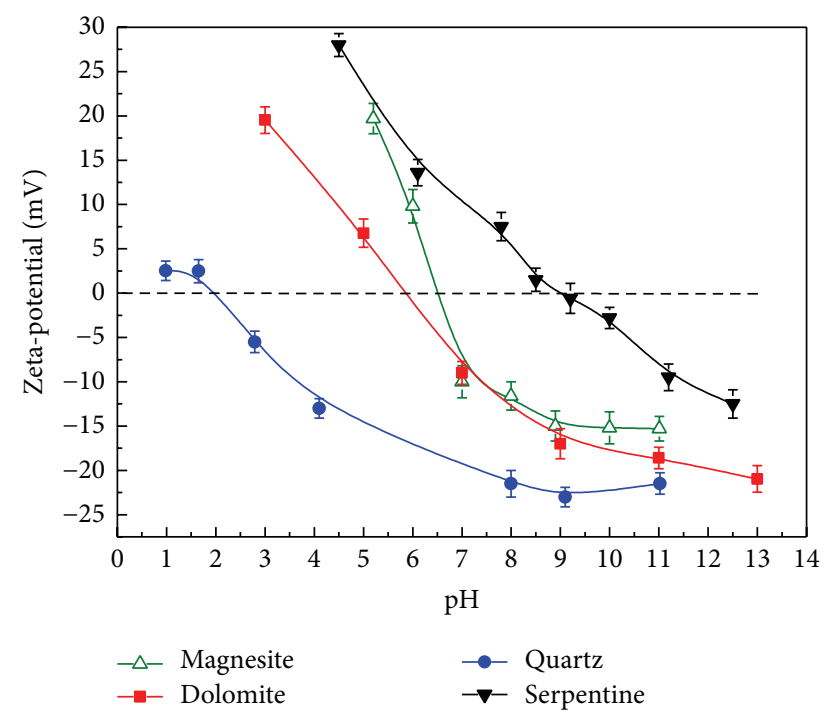

FIGURE 12: Influence of $\mathrm{pH}$ on zeta-potential of magnesite, dolomite, serpentine, and quartz.

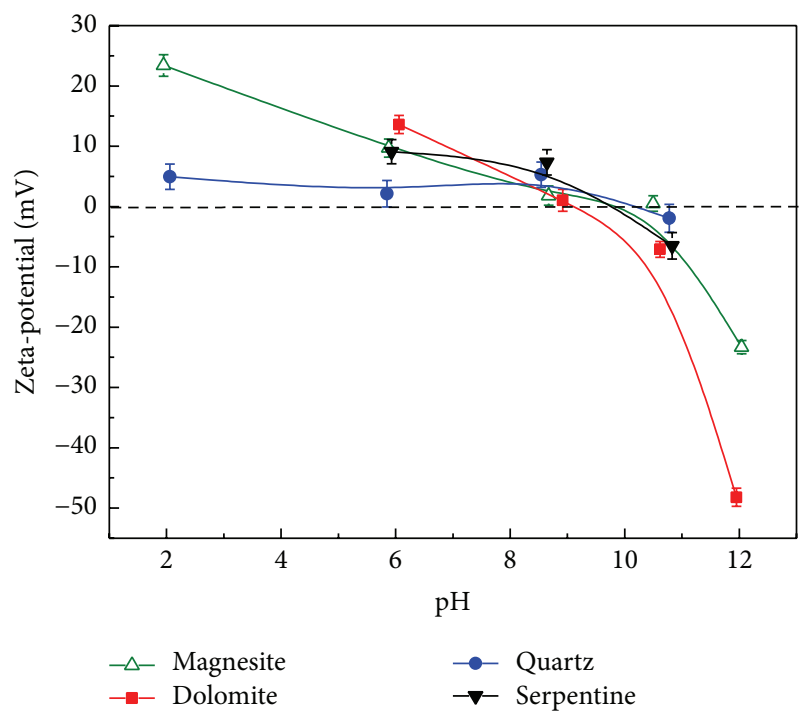

FIGURE 13: Influence of $\mathrm{pH}$ on zeta-potential of magnesite, dolomite, serpentine, and quartz in DDA solution $\left(8.6 \times 10^{-4} \mathrm{M}\right)$.

4.4. Wettability and Surface Tension. The practical conditions under which contact angles are measured are far from those required to satisfy Young's equation, which requires the solid surfaces to be chemically homogenous, smooth, flat, nonporous, insoluble, nondeformable, and nonreactive [4447]. The observed contact angles when the liquid is advancing over a dry surface or receding from a wet surface are taken as the advancing contact angle and receding contact angle, respectively. The differences between these two types of contact angles are noticeable on all rough or dirty surfaces, which is referred to as contact angle hysteresis. The receding contact angle is often preferred for flotation systems because it offers better commitment with flotation response, as was verified in several studies [48-52], and it is used in this study.
TABLE 2: Average receding contact angle with and without surfactants in deionized water and glycerin $\left(\theta^{\circ}\right)$.

\begin{tabular}{lcccccccc}
\hline \multirow{2}{*}{ Minerals } & \multicolumn{2}{c}{ Magnesite } & \multicolumn{2}{c}{ Dolomite } & \multicolumn{2}{c}{ Serpentine } & \multicolumn{2}{c}{ Quartz } \\
& DW & DDA & DW & DDA & DW & DDA & DW & DDA \\
\hline DW & 1.3 & 1.6 & 22 & 88 & 20 & 21 & 0 & 136 \\
GC & 62 & 41 & 28 & 104 & 78 & 28 & 45 & 138 \\
\hline
\end{tabular}

Note: DW: distilled water; DDA: dodecylamine; and GC: glycerin.

TABLE 3: Surface tension parameters of water and glycerin.

\begin{tabular}{lcccc}
\hline Species & $\gamma_{L}\left(\mathrm{~mJ} / \mathrm{m}^{2}\right)$ & $\gamma_{L}^{d}\left(\mathrm{~mJ} / \mathrm{m}^{2}\right)$ & $\gamma_{L}^{+}\left(\mathrm{mJ} / \mathrm{m}^{2}\right)$ & $\gamma_{L}^{-}\left(\mathrm{mJ} / \mathrm{m}^{2}\right)$ \\
\hline Water & 72.8 & 21.8 & 25.5 & 25.5 \\
Glycerin & 64 & 34 & 3.92 & 57.4 \\
\hline
\end{tabular}

TABle 4: Values of components of surface energies and Hamaker constants of magnesite, dolomite, and quartz.

\begin{tabular}{lccc}
\hline Species & $A\left(10^{-20} \mathrm{~J}\right)$ & $\gamma_{S}^{d}\left(\mathrm{Mj} / \mathrm{m}^{2}\right)$ & $\gamma_{S}^{-}\left(\mathrm{Mj} / \mathrm{m}^{2}\right)$ \\
\hline Magnesite & 4.38 & 21.35 & 102.87 \\
Dolomite & 13.75 & 67.07 & 39.91 \\
Serpentine & 1.54 & 66.7 & 40.77 \\
Quartz & 8.72 & 42.55 & 70.29 \\
\hline
\end{tabular}

The measured receding contact angle values at the magnesite, dolomite, and quartz surfaces in distilled water and glycerin in the absence and presence of surfactant DDA are given in Table 2. The contact angle measurements showed that the magnesite, dolomite, serpentine, and quartz minerals have no natural floatability, as indicated by a small contact angle in distilled water. Table 2 shows that surfactant DDA caused an obvious increase in the contact angle at the quartz and dolomite surfaces but hardly any increase at the magnesite and serpentine surface. The results indicate that the hydrophobicity of the quartz surface improved significantly after treatment with DDA. In contrast, the hydrophobicity of dolomite improved slightly in the presence of DDA, and that of magnesite and serpentine remained almost still.

Table 3 shows the known values of the surface energy components of water and glycerin. The Hamaker constants and values for the components of the surface energy of magnesite, dolomite, and quartz are calculated on the basis of (12)-(13) and presented in Table 4.

4.5. Interaction Energy and Aggregation Evaluation. Based on (1) (13), the van der Waals interaction energies, electrical interaction energies, and polar interfacial interaction energies between magnesite, dolomite, serpentine, and quartz particles in the absence and presence of DDA $\left(8.6 \times 10^{-4} \mathrm{M}\right)$ at $\mathrm{pH} 9.5$ are calculated and illustrated in Figures 14-18. It can be seen that the strength and distribution of $V_{W}, V_{E}$, and $V_{H}$ interactions are different from each other, which results in a complex profile of total E-DLVO interaction energy.

The total interaction energies are calculated. Figure 19 illustrates the interaction energy between magnesite, dolomite, serpentine, and quartz particles at $\mathrm{pH}$ 9.5. The DLVO energy profiles indicate that the interaction energy at 


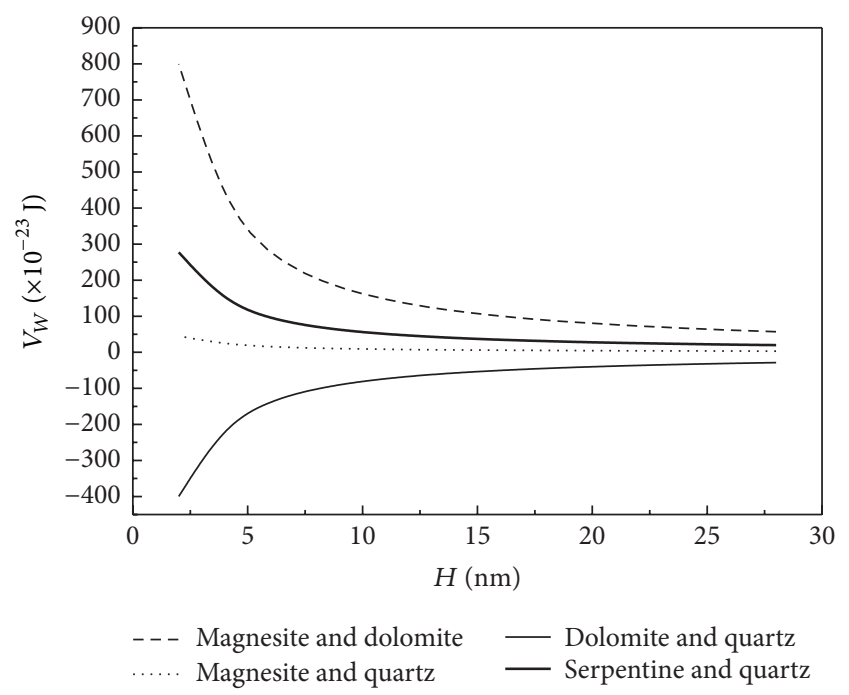

FIGURE 14: van der Waals interaction energy between mineral particles.

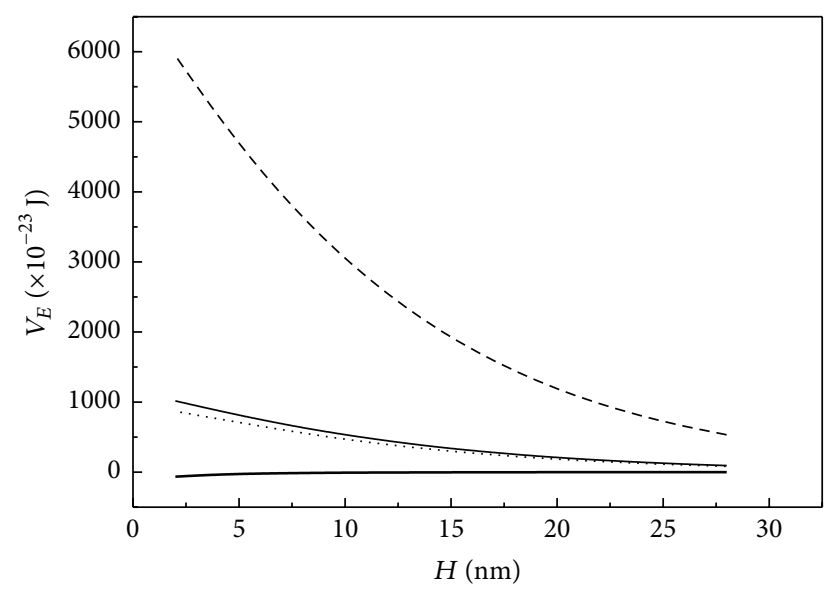

$$
\begin{aligned}
& \mathrm{pH}=9.5 \\
& \text { - - Magnesite and dolomite — Dolomite and quartz } \\
& \text {..... Magnesite and quartz _ _ Serpentine and quartz } \\
& \text { (in absence of DDA) }
\end{aligned}
$$

FIGURE 15: Electrical interaction energy between mineral particles in absence of DDA.

pH 9.5 in the absence and presence of DDA will be almost the same because the classical DLVO theory only considers van der Waals and electrostatic energy, which cannot estimate the change in interfacial interaction energy caused by surface wettability variations. It cannot explain the different interaction behaviors in flotation shown in Figures 7-10. However, the Extended-DLVO energy profiles exhibit an evident repulsion between magnesite and quartz, serpentine and quartz, and dolomite and quartz particles in the absence of DDA and a strong attraction in the presence of $8.6 \times$ $10^{-4} \mathrm{M}$ DDA at $\mathrm{pH} 9.5$, as shown in Figure 19, which indicate that hydrophobic aggregation occurs between magnesite and quartz particles, serpentine and quartz particles, and dolomite and quartz particles adsorbing DDA; this result

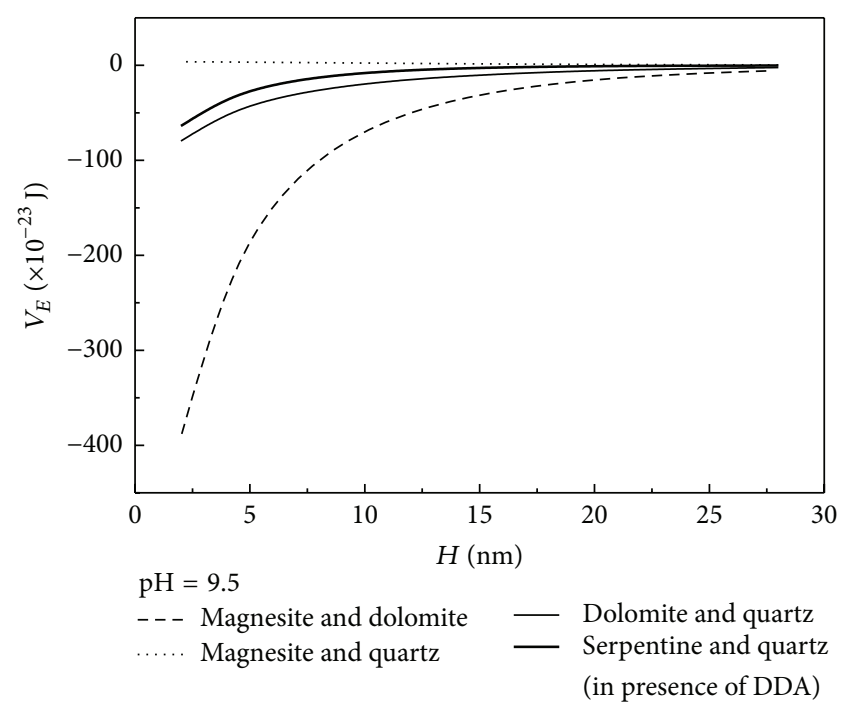

FIGURE 16: Electrical interaction energy between mineral particles in presence of DDA.

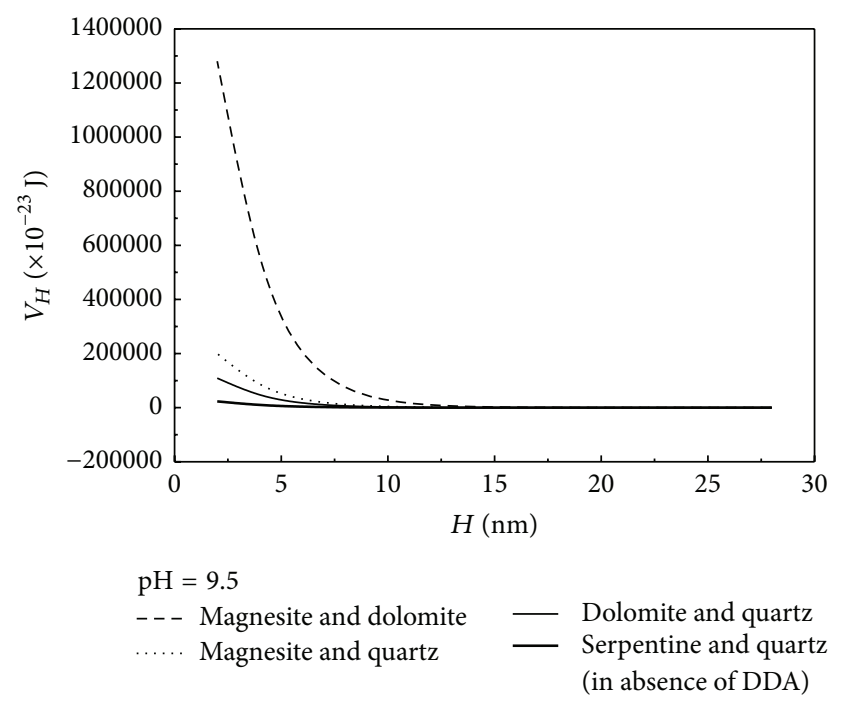

FIgURE 17: Polar interfacial interaction energy between mineral particles in absence of DDA.

agrees with the microflotation and SEM analysis results. The results of flotation test and theoretical calculation together with SEM analysis have proved that the fine magnesite, dolomite, and serpentine particles can decrease the float recovery of quartz by masking on its surface, thus reducing the hydrophobicity of the quartz surface and preventing quartz from being collected by DDA. It is thus proved that the Extended-DLVO theory can be used to devise a criterion for evaluating the aggregation of particles in flotation processes.

Under ideal flotation or single mineral flotation conditions, some minerals should be easily adsorbed by the collector and float up with air bubble. However, in actual ore flotation, many mineral particles of various sizes exist together and the particles having attractive interaction force tend to aggregate, and when the fine hydrophilic particles mask on 


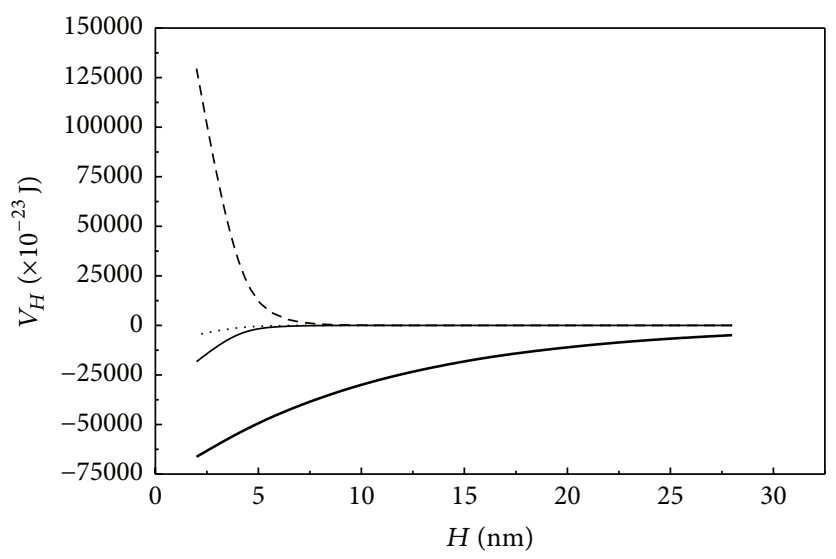

$$
\begin{aligned}
& \mathrm{pH}=9.5 \\
& \text { - - - Magnesite and dolomite __ Dolomite and quartz } \\
& \text {..... Magnesite and quartz _- Serpentine and quartz } \\
& \text { (in presence of DDA) }
\end{aligned}
$$

FIGURE 18: Polar interfacial interaction energy between mineral particles in presence of DDA.
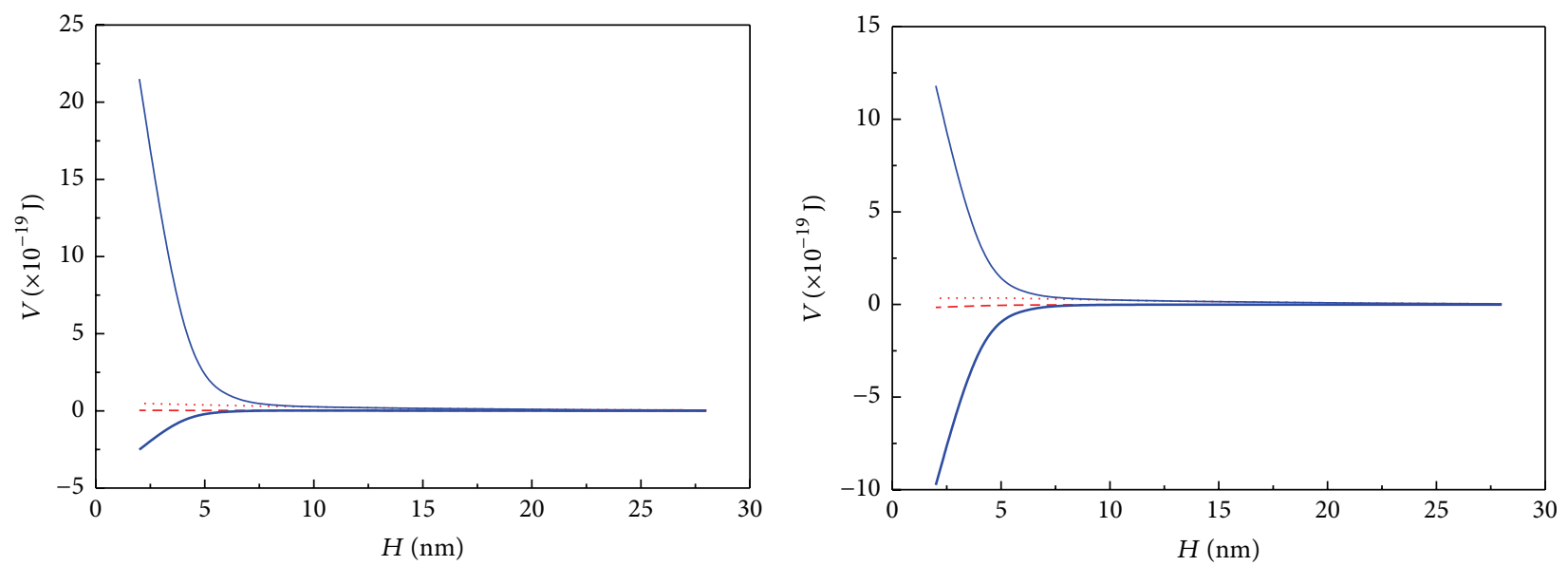

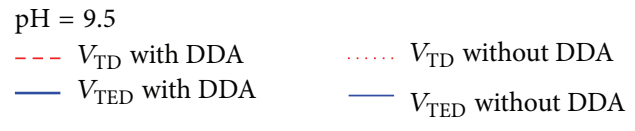

(a)

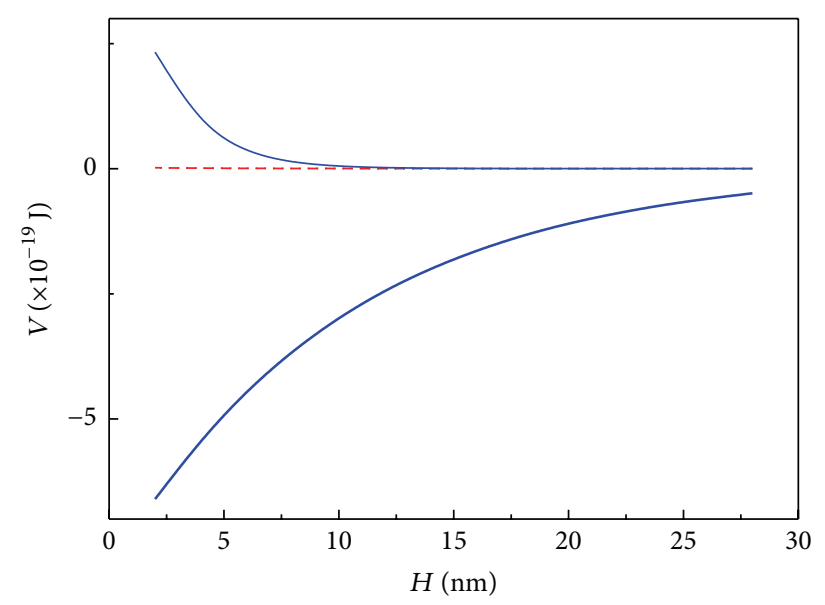

$\mathrm{pH}=9.5$

- - $V_{\text {TD }}$ with DDA

$-V_{\mathrm{TED}}$ with DDA $\cdots . . . V_{\mathrm{TD}}$ without DDA
$-V_{\mathrm{TED}}$ without DDA

(c)

$$
\begin{aligned}
& \mathrm{pH}=9.5 \\
& \text { - - } V_{\mathrm{TD}} \text { with DDA } \\
& \text { - } V_{\text {TED }} \text { with DDA } \\
& \text {..... } V_{\mathrm{TD}} \text { without DDA } \\
& -V_{\mathrm{TED}} \text { without DDA }
\end{aligned}
$$

(b)

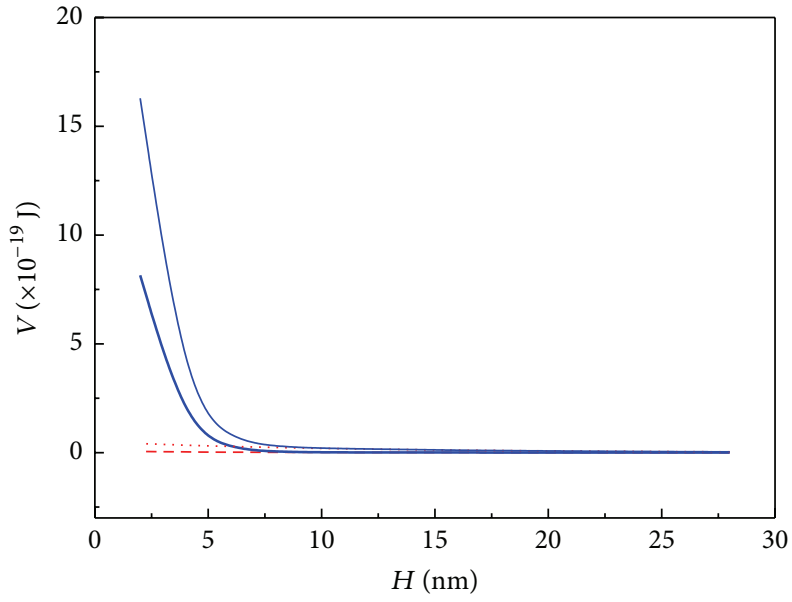

$$
\begin{aligned}
& \mathrm{pH}=9.5 \\
& ---V_{\mathrm{TD}} \text { with DDA } \\
& -V_{\mathrm{TED}} \text { with DDA }
\end{aligned}
$$

(d)

FIGURE 19: DLVO and the Extended-DLVO interaction energy profiles for magnesite, dolomite, and quartz in the presence and absence of DDA; (a) magnesite and quartz; (b) dolomite and quartz; (c) serpentine and quartz; and (d) magnesite and dolomite. 


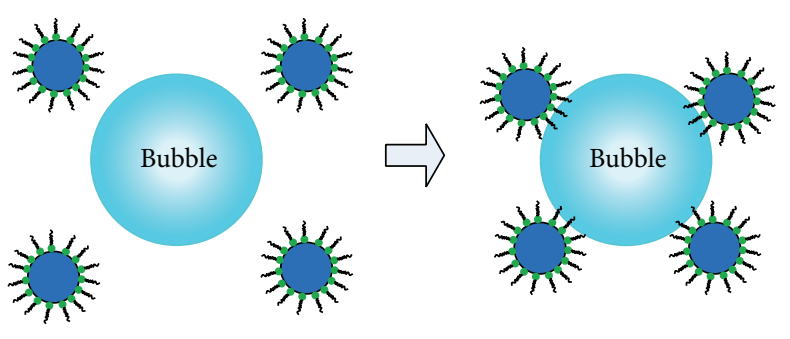

Flotation without fine particles adsorbing on quartz surfaces

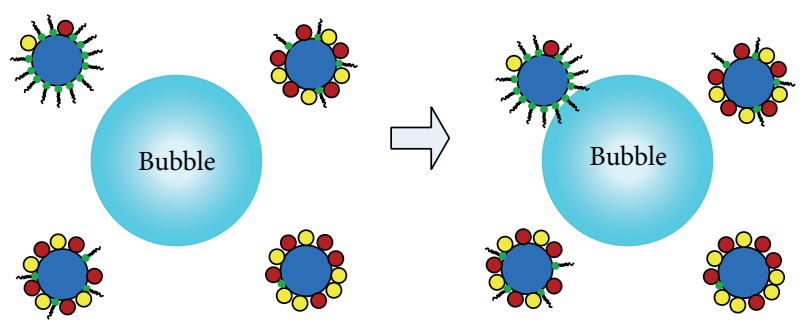

Flotation with fine particles adsorbing on quartz surfaces

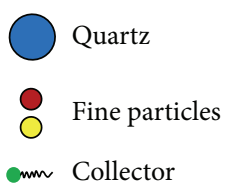

FIgURE 20: Mechanisms of the "suppression" caused by masking effect of fine particles in flotation.

the surface of hydrophobic surface of coarse particles, an apparently "suppressing effect" occurs. The mechanism of the "suppressing effect" caused by fine particles is illustrated in Figure 20. In ideal single mineral flotation, quartz will be adsorbed by DDA and float with the air bubbles, as illustrated in Figure 20(a), but, in the actual ore flotation processes, fine magnesite, dolomite, and serpentine particles are easily adsorbed on the quartz surface, thus reducing the chance that quartz comes into contact with air bubbles and decreasing the recovery of quartz, as illustrated in Figure 20(b).

\section{Conclusion}

The proof for the interacting phenomenon of fine and coarse particle of different minerals is discussed, together with the calculation method for its determination based on the Extended-DLVO theory. Some valuable original data including the zeta-potential, contact angle, and surface tension of magnesite, dolomite, serpentine, and quartz in the presence and absence of DDA were measured in this study, which can be used as reference in future research.

The discovered phenomenon is universal in flotation process, in which fine mineral particles can mask on the surface of coarse particles of another mineral and thus decrease or increase the recovery of the coarse particles. The influence of particles size [53] and particles interaction on flotation was previously related to many factors such as particle aggregation, flocculation, entrainment, and carrier flotation $[13,54,55]$. However, a clear suppressing effect from one mineral to another has rarely been mentioned, yet it is significant for flotation processes, as demonstrated above. The masking of fine hydrophilic particles on the surface of hydrophobic minerals can prevent it from being collected, leading to the apparent "suppressing" effect. However, the extent and severity of surface masking and the difficulty of collecting the masked particles remain unclear.

The single mineral and artificial mixed minerals flotation results showed that fine magnesite, dolomite, and serpentine particles could suppress the flotation of coarse quartz, which reduced the flotation recovery of quartz by up to $59.51 \%$, $16.12 \%$, and $48.58 \%$, respectively. The calculation method based on Extended-DLVO theory can quantitatively explain the mechanisms of suppressing effect of fine particles on coarse particles, which is also an important criterion on judging aggregation behavior of mineral particles in flotation. The interfacial interaction energy determining the aggregating behavior agreed well with the experimental results and can thus be a criterion for determining the occurrence of masking interaction. Considering the calculation components of the interaction energy, some indications of dispersing measurements are promising, such as modification of the surface potential, wettability, and surface tension by controlling the $\mathrm{pH}$ or adding effective dispersants.

\section{Competing Interests}

The authors declare that they have no competing interests.

\section{Acknowledgments}

The authors would like to acknowledge the financial support from the National Science Foundation of China (no. 51374079, no 51504053), the China Postdoctoral Science Foundation (no. 2015M571324), the Ph.D. start-up foundation of Science and Technology Department of Liaoning Province (20151157), and the foundation of Education Department of Liaoning Province (L20150180).

\section{References}

[1] O. Laitinen, R. Hartmann, J. A. Sirviö et al., "Alkyl aminated nanocelluloses in selective flotation of aluminium oxide and quartz," Chemical Engineering Science, vol. 144, pp. 260-266, 2016.

[2] X. Gui, J. Liu, Y. Cao, G. Cheng, S. Li, and L. Wu, "Flotation process design based on energy input and distribution," Fuel Processing Technology, vol. 120, pp. 61-70, 2014.

[3] J. Amaral Filho, A. Azevedo, R. Etchepare, and J. Rubio, "Removal of sulfate ions by dissolved air flotation (DAF) following precipitation and flocculation," International Journal of Mineral Processing, vol. 149, pp. 1-8, 2016.

[4] F. Iselau, P. Restorp, M. Andersson, and R. Bordes, "Role of the aggregation behavior of hydrophobic particles in paper surface hydrophobation," Colloids and Surfaces A: Physicochemical and Engineering Aspects, vol. 483, pp. 264-270, 2015. 
[5] L. Liang, Y. Wang, and Z. Pan, "Prediction of aggregation behavior of submicron-sized particles of praseodymium-doped zirconium silicate in aqueous suspension by population balance model," Particuology, vol. 25, pp. 83-92, 2016.

[6] L. Xu, Y. Hu, J. Tian et al., "Synergistic effect of mixed cationic/anionic collectors on flotation and adsorption of muscovite," Colloids and Surfaces A: Physicochemical and Engineering Aspects, vol. 492, pp. 181-189, 2016.

[7] J. Yao, W. Yin, and E. Gong, "Depressing effect of fine hydrophilic particles on magnesite reverse flotation," International Journal of Mineral Processing, vol. 149, pp. 84-93, 2016.

[8] H. Sahoo, S. S. Rath, D. S. Rao, B. K. Mishra, and B. Das, "Role of silica and alumina content in the flotation of iron ores," International Journal of Mineral Processing, vol. 148, pp. 83-91, 2016.

[9] B. Yu, X. Che, and Q. Zheng, "Flotation of ultra-fine rare-earth minerals with selective flocculant PDHA," Minerals Engineering, vol. 60, pp. 23-25, 2014.

[10] B. Wang, Y. Peng, and S. Vink, "Effect of saline water on the flotation of fine and coarse coal particles in the presence of clay minerals," Minerals Engineering, vol. 66-68, pp. 145-151, 2014.

[11] S. Song, X. Zhang, B. Yang, and A. Lopez-Mendoza, "Flotation of molybdenite fines as hydrophobic agglomerates," Separation and Purification Technology, vol. 98, pp. 451-455, 2012.

[12] X. Gui, G. Cheng, J. Liu, Y. Cao, S. Li, and Q. He, "Effects of energy consumption on the separation performance of fine coal flotation," Fuel Processing Technology, vol. 115, pp. 192-200, 2013.

[13] W. S. Ng, R. Sonsie, E. Forbes, and G. V. Franks, "Flocculation/flotation of hematite fines with anionic temperatureresponsive polymer acting as a selective flocculant and collector," Minerals Engineering, vol. 77, pp. 64-71, 2015.

[14] Y. Peng and S. Zhao, "The effect of surface oxidation of copper sulfide minerals on clay slime coating in flotation," Minerals Engineering, vol. 24, no. 15, pp. 1687-1693, 2011.

[15] E. Forbes, K. J. Davey, and L. Smith, "Decoupling rehology and slime coatings effect on the natural flotability of chalcopyrite in a clay-rich flotation pulp," Minerals Engineering, vol. 56, pp. 136144,2014

[16] X. Lei, Y. Chen, Z. Shao et al., "Effective harvesting of the microalgae Chlorella vulgaris via flocculation-flotation with bioflocculant," Bioresource Technology, vol. 198, pp. 922-925, 2015.

[17] H. Yang, Q. Tang, C. Wang, and J. Zhang, "Flocculation and flotation response of Rhodococcus erythropolis to pure minerals in hematite ores," Minerals Engineering, vol. 45, pp. 6772, 2013.

[18] A. G. Lange, W. M. Skinner, and R. S. C. Smart, "Fine: coarse particle interactions and aggregation in sphalerite flotation," Minerals Engineering, vol. 10, no. 7, pp. 681-693, 1997.

[19] S. Lu and S. Song, "Hydrophobic interaction in flocculation and flotation 1. Hydrophobic flocculation of fine mineral particles in aqueous solution," Colloids and Surfaces, vol. 57, no. 1, pp. 49-60, 1991.

[20] B. Vincent, "Early (pre-DLVO) studies of particle aggregation," Advances in Colloid and Interface Science, vol. 170, no. 1-2, pp. 56-67, 2012.

[21] B. V. Derjaguin and N. V. Churaev, "The current state of the theory of long-range surface forces," Colloids and Surfaces, vol. 41, pp. 223-237, 1989.

[22] B. W. Ninham, "On progress in forces since the DLVO theory," Advances in Colloid and Interface Science, vol. 83, no. 1, pp. 1-17, 1999.
[23] R.-H. Yoon and L. Mao, "Application of extended DLVO theory, IV: derivation of flotation rate equation from first principles," Journal of Colloid and Interface Science, vol. 181, no. 2, pp. 613626, 1996.

[24] Y. Hu and J. Dai, "Hydrophobic aggregation of alumina in surfactant solution," Minerals Engineering, vol. 16, no. 11, pp. 1167-1172, 2003.

[25] E. J. W. Verwey and J. T. G. Overbeek, "Theory of the stability of lyophobic colloids," Journal of Colloid Science, vol. 10, no. 2, pp. 224-225, 1955.

[26] J. H. Schenkel and J. A. Kitchener, "A test of the DerjaguinVerwey-Overbeek theory with a colloidal suspension," Transactions of the Faraday Society, vol. 56, pp. 161-173, 1960.

[27] R. Hogg, T. W. Healy, and D. W. Fuerstenau, "Mutual coagulation of colloidal dispersions," Transactions of the Faraday Society, vol. 62, pp. 1638-1651, 1966.

[28] R. J. Pugh and J. A. Kitchener, "Theory of selective coagulation in mixed colloidal suspensions," Journal of Colloid And Interface Science, vol. 35, no. 4, pp. 656-664, 1971.

[29] J. Israelachvili and R. Pashley, "The hydrophobic interaction is long range, decaying exponentially with distance," Nature, vol. 300, no. 5890, pp. 341-342, 1982.

[30] P. M. Claesson, C. E. Blom, P. C. Herder, and B. W. Ninham, "Interactions between water-stable hydrophobic LangmuirBlodgett monolayers on mica," Journal of Colloid And Interface Science, vol. 114, no. 1, pp. 234-242, 1986.

[31] D. Y. C. Chan, D. J. Mitchell, B. W. Ninham, and B. A. Pailthorpe, "Dispersion interactions across binary liquid mixtures. A proper account of structural effects," Journal of Colloid And Interface Science, vol. 68, no. 3, pp. 462-470, 1979.

[32] H. K. Christenson and P. M. Claesson, "Cavitation and the interaction between macroscopic hydrophobic surfaces," Science, vol. 239, no. 4838, pp. 390-392, 1988.

[33] C. J. Van Oss, Interfacial Forces in Aqueous Media, Marcel Dekker, New York, NY, USA, 2nd edition, 2006.

[34] C. J. van Oss, R. F. Giese, and P. M. Costanzo, "DLVO and nonDLVO interactions in hectorite," Clays \& Clay Minerals, vol. 38, no. 2, pp. 151-159, 1990.

[35] C. J. Oss, R. J. Good, and M. K. Chaudhury, "Determination off the hydrophobia interaction energy-application to separation processes," Separation Science and Technology, vol. 22, no. 1, pp. $1-24,1987$.

[36] C. J. van Oss, M. K. Chaudhury, and R. J. Good, "Monopolar surfaces," Advances in Colloid and Interface Science, vol. 28, pp. 35-64, 1987.

[37] C. J. Van Oss, M. K. Chaudhury, and R. J. Good, "Interfacial Lifshitz-van der Waals and polar interactions in macroscopic systems," Chemical Reviews, vol. 88, no. 6, pp. 927-941, 1988.

[38] C. J. Van Oss and R. J. Good, "Surface tension and the solubility of polymers and biopolymers: the role of polar and apolar interfacial free energies," Journal of Macromolecular Science A. Chemistry, vol. 26, no. 8, pp. 1183-1203, 1989.

[39] L. Bergström, "Hamaker constants of inorganic materials," Advances in Colloid and Interface Science, vol. 70, pp. 125-169, 1997.

[40] P. G. Smith and L. J. Warren, "Entrainment of particles into flotation froths," Mineral Processing and Extractive Metallurgy Review, vol. 5, no. 1-4, pp. 123-145, 1989.

[41] E. C. Cilek, "The effect of hydrodynamic conditions on true flotation and entrainment in flotation of a complex sulphide ore," International Journal of Mineral Processing, vol. 90, no. 1-4, pp. 35-44, 2009. 
[42] A. Hubbard, "Colloidal science of flotation: by Anh V. Nguyen and Hans Joachim Schulze. Marcel Dekker, New York, 2004, 850 pp.," Journal of Colloid and Interface Science, vol. 273, no. 1, p. 343, 2004.

[43] O. N. Savassi, D. J. Alexander, J. P. Franzidis, and E. V. Manlapig, "An empirical model for entrainment in industrial flotation plants," Minerals Engineering, vol. 11, no. 3, pp. 243-256, 1998.

[44] H. Tavana, C. N. C. Lam, K. Grundke et al., "Contact angle measurements with liquids consisting of bulky molecules," Journal of Colloid and Interface Science, vol. 279, no. 2, pp. 493502, 2004.

[45] C.-T. Lin and K.-L. Lin, "Contact angle of $63 \mathrm{Sn}-37 \mathrm{~Pb}$ and $\mathrm{Pb}-$ free solder on Cu plating," Applied Surface Science, vol. 214, no. 1-4, pp. 243-258, 2003.

[46] S. A. Shedid and M. T. Ghannam, "Factors affecting contactangle measurement of reservoir rocks," Journal of Petroleum Science and Engineering, vol. 44, no. 3-4, pp. 193-203, 2004.

[47] C. N. C. Lam, R. Wu, D. Li, M. L. Hair, and A. W. Neumann, "Study of the advancing and receding contact angles: liquid sorption as a cause of contact angle hysteresis," Advances in Colloid and Interface Science, vol. 96, no. 1-3, pp. 169-191, 2002.

[48] N. Gence, "Wetting behavior of magnesite and dolomite surfaces," Applied Surface Science, vol. 252, no. 10, pp. 3744-3750, 2006.

[49] C. N. C. Lam, R. H. Y. Ko, L. M. Y. Yu et al., "Dynamic cycling contact angle measurements: study of advancing and receding contact angles," Journal of Colloid and Interface Science, vol. 243, no. 1, pp. 208-218, 2001.

[50] J. S. Kim, R. H. Friend, and F. Cacialli, "Surface wetting properties of treated indium tin oxide anodes for polymer lightemitting diodes," Synthetic Metals, vol. 111-112, pp. 369-372, 2000.

[51] A. Yehia and M. I. Al-Wakeel, "Talc separation from talccarbonate ore to be suitable for different industrial applications," Minerals Engineering, vol. 13, no. 1, pp. 111-116, 2000.

[52] D. Y. Kwok and A. W. Neumann, "Contact angle measurement and contact angle interpretation," Advances in Colloid and Interface Science, vol. 81, no. 3, pp. 167-249, 1999.

[53] S. V. C. Bravo, M. L. Torem, M. B. M. Monte, A. J. B. Dutra, and L. A. Tondo, "The influence of particle size and collector on the flotation of a very low grade auriferous ore," Minerals Engineering, vol. 18, no. 4, pp. 459-461, 2005.

[54] J. Liu, X. Wang, C.-L. Lin, and J. D. Miller, "Significance of particle aggregation in the reverse flotation of kaolinite from bauxite ore," Minerals Engineering, vol. 78, pp. 58-65, 2015.

[55] L. Wang, Y. Peng, K. Runge, and D. Bradshaw, "A review of entrainment: mechanisms, contributing factors and modelling in flotation," Minerals Engineering, vol. 70, pp. 77-91, 2015. 


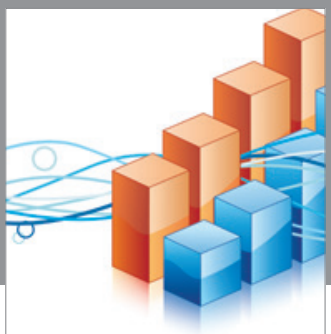

Advances in

Operations Research

vatem alat4

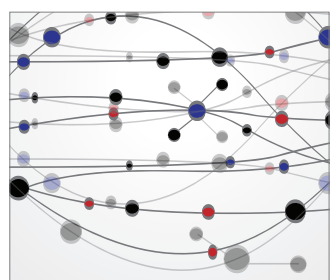

\section{The Scientific} World Journal
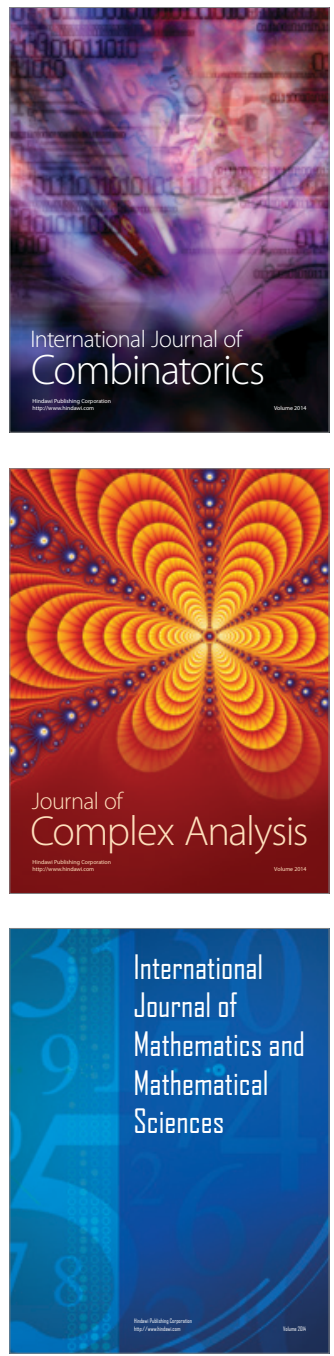
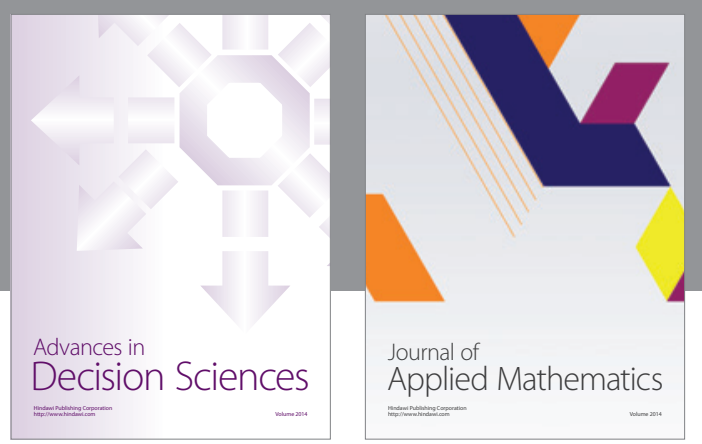

Algebra

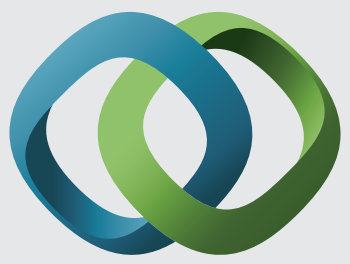

\section{Hindawi}

Submit your manuscripts at

http://www.hindawi.com
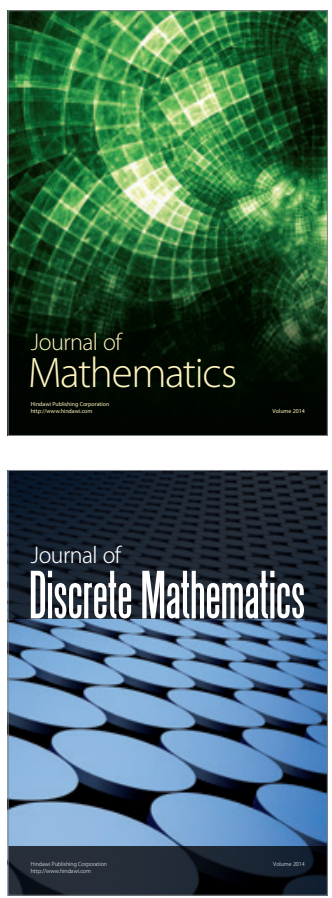

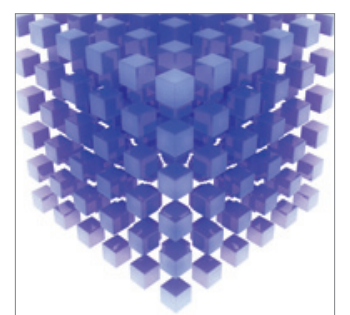

Mathematical Problems in Engineering
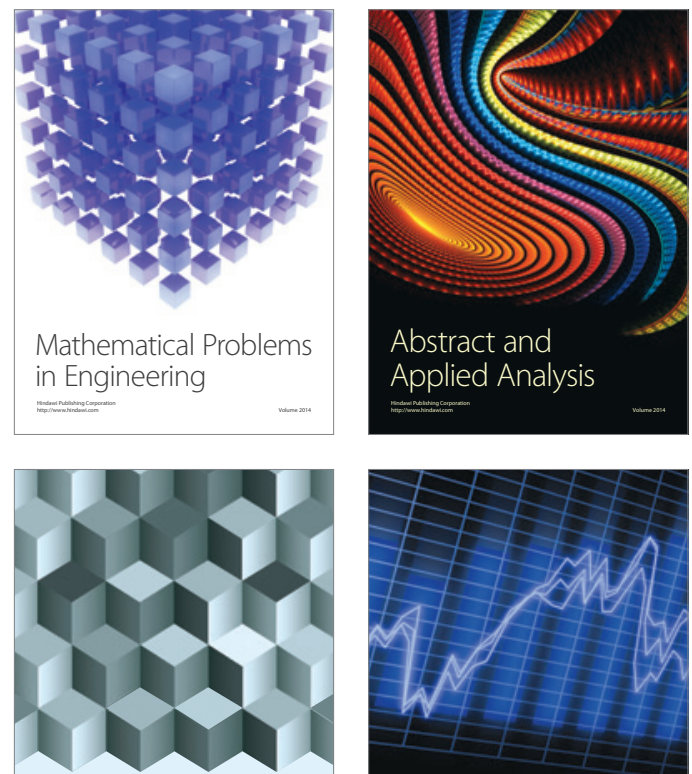

Journal of

Function Spaces

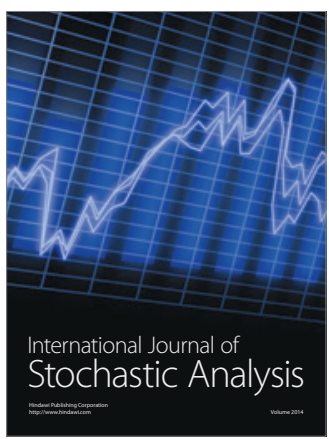

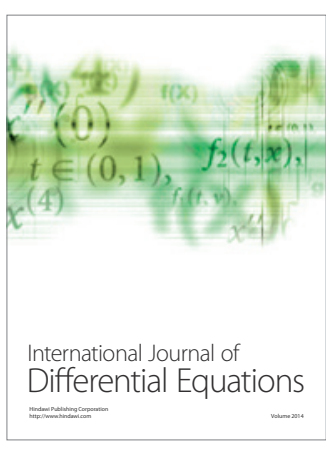
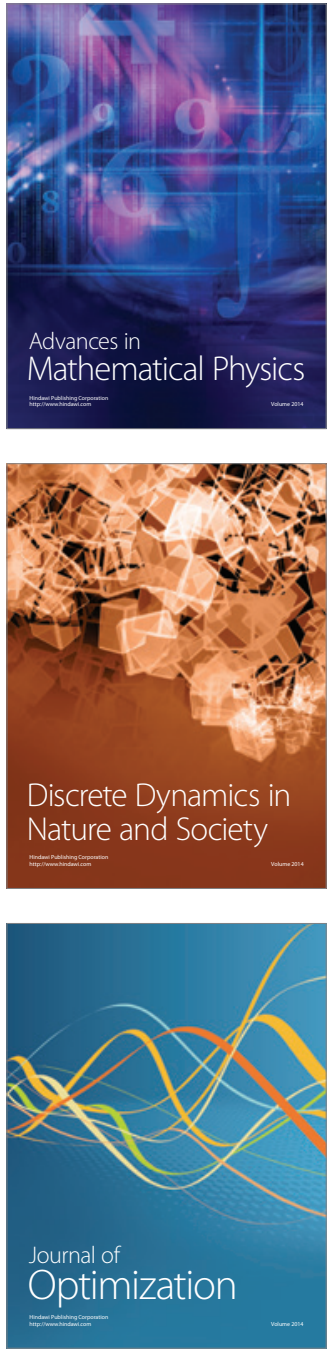